\title{
Multiscale Composites of Kevlar Fibers and Carbon Nanotubes in Epoxy Matrix
}

\author{
Numrah Sultan ${ }^{1, ~ *, ~ M a d i h a ~ N a z i r ~}{ }^{1}$, Urooj Zahra Khan ${ }^{1}$, Tayyab Subhani ${ }^{2}$ \\ ${ }^{1}$ Composite Research Center, Department of Materials Science and Engineering, Institute of Space Technology, Islamabad, Pakistan \\ ${ }^{2}$ Department of Mechanical Engineering, College of Engineering, University of Ha'il, Ha'il, Saudi Arabia
}

\section{Email address:}

numrahsultan@hotmail.com (N. Sultan),madeehanazeee92@gmail.com (M. Nazir),uroojxara@gmail.com (U. Z. Khan), drtayyabsubhani@gmail.com (T. Subhani)

${ }^{*}$ Corresponding author

\section{To cite this article:}

Numrah Sultan, Madiha Nazir, Urooj Zahra Khan, Tayyab Subhani. Multiscale Composites of Kevlar Fibers and Carbon Nanotubes in Epoxy Matrix. American Journal of Nano Research and Applications. Vol. 9, No. 2, 2021, pp. 9-15. doi: 10.11648/j.nano.20210902.11

Received: September 23, 2021; Accepted: October 12, 2021; Published: October 21, 2021

\begin{abstract}
Hybrid composites with high strength to weight ratio are very important in structural applications. An extensive research is being carried out to enhance the mechanical properties of composites by incorporating micro and nanoscale reinforcements. The nanoreinforcements provide unique strengthening mechanisms that result in an overall high mechanical performance of composites. In order to investigate the effect of nanoreinforcements on the mechanical properties of fiber reinforced composites a novel multiscale composites of Kevlar fibers and carbon nanotubes in epoxy matrix were prepared in this research. A combination of hand layup and vacuum bagging technique was used to manufacture multiscale composites. Nanotubes at three different concentrations, i.e. $0.33 \mathrm{wt} \%, 0.66 \mathrm{wt} \%$ and $0.99 \mathrm{wt} \%$ were incorporated after their functionalization through ultraviolet ozone-treatment to improve their interfacial interaction with epoxy matrix. The microstructural and mechanical property characterization of multiscale composites was performed by optical and electron microscopy, and tensile, hardness and interlaminar shear testing. An increase of $\sim 45 \%$ in tensile strength was noted by incorporating $0.99 \mathrm{wt} \%$ of nanotubes while the improvements of $\sim 60 \%$ in hardness and $\sim 13 \%$ rise in interlaminar shear strength were observed. The improved mechanical performance owes to the uniform dispersion of nanotubes along with their adherence to nanotubes promoting anchoring effect between fibers and matrix.
\end{abstract}

Keywords: Carbon Nanotubes, Kevlar Fibers, Epoxy, Multiscale Composites, Hardness, Tensile Strength

\section{Introduction}

The advent of nanotechnology has revolutionized the field of composites by introducing a novel class of nanocomposites, which contain the reinforcement with one of its dimensions less than $100 \mathrm{~nm}$. Among all nanoreinforcements, carbon nanotubes (CNTs) are one of the most widely investigated, which is due to their exceptional mechanical properties: elastic modulus of $\sim 1.8 \mathrm{TPa}$ and tensile strength of $\sim 110 \mathrm{GPa}$ [1]. CNTs both single walled carbon nanotubes (SWCNTs) and multiwalled carbon nanotubes (MWCNTs) are made up of rolled graphene sheets in the form of cylinders with their ends capped by hemisphere of fullerene; their aspect ratio can be greater than $\sim 1000$ with diameter in nanometer size [2]. In manufacturing polymeric matrix composites (PMCs) containing CNTs, the uniform dispersion of CNTs has been the major issue, which has been resolved by the availability of various functionalization techniques such as fluorination, acidtreatment, reactive plasma and ultraviolet ozone-treatment [3].

In addition to nanocomposites containing single reinforcement, a type of hybrid composites, i.e. multiscale composites have also gained attention in recent years, which contain at least two reinforcements with their sizes at two different scales [4]; typically nanometer size reinforcements are used along with traditional micrometer size fibers of glass, carbon and Kevlar. In comparison to composites containing 
glass and carbon fibers, the composites containing Kevlar fibers are less investigated with nanoreinforcements. Kevlar ${ }^{\circledR}$ is the trade name of para-aramid fibers, which have characteristic anisotropy: strong covalent bonding between molecular chains offers a high longitudinal strength whereas hydrogen bonding between the amide linkages results in relatively weak transverse strength. In particular, Kevlar fibers have high impact resistance due to their fibril failure. The fibrils break individually and absorb a considerable amount of energy before the final failure takes place; this molecular level energy dissipation mechanism is the cause of high impact strength of Kevlar fibers [5]. However, Kevlar fibers have poor interfacial interaction with the matrix due to their low surface energy and chemically stable structure. The surface modification techniques are therefore used to counter this problem and acquire an optimum interfacial interaction [6, 7].

CNTs are added in PMCs alone or in combination with other nanometer-scale and micrometer-scale reinforcements to study their individual and combined reinforcing effect [4-8]. The addition of CNTs in epoxy causes an increase in tensile strength of composites up to a certain extent [9] while their addition with micrometer-size fibers like carbon fiber or glass fibers results in the significant rise [10-15]. In addition to tensile strength, CNTs also play an important role in increasing the shear strength of traditional composites. In a study [16], it was observed that interlaminar shear strength of glass fiber epoxy matrix composites increased after the addition of $\mathrm{NH}_{2}-$ CNTs due to improved interfacial bonding. Likewise $8 \%$ improvement in shear strength was also observed in carbon fiber epoxy matrix composites containing CNTs [17]. In addition to shear strength, the impact strength of composites also increased with the addition of CNTs. In a report [18], the addition of CNTs in limited quantity of $0.5 \mathrm{wt} \%$ has shown $35 \%$ rise in impact strength of Kevlar fiber epoxy matrix composites. Other nanoreinforcements like cork powder and nanoclay are also reported to improve the impact strength of Kevlar fiber epoxy matrix composites [19, 20].

Due to the growing interest of fabricating advanced composites to cater the needs of aerospace and automotive industries, there is an urgent need to investigate the true effect of incorporating CNTs in Kevlar fiber epoxy matrix composites on their mechanical properties so that the research on multiscale composites containing CNTs could be realized in engineering industry.

In the present work, the effect of MWCNTs on the mechanical properties of Kevlar fiber epoxy matrix composites was explored. MWCNTs were functionalized through ultraviolet ozone-treatment and subsequently added in epoxy at three different weight fractions. A combination of hand layup and vacuum bagging techniques was used to manufacture composites. The fabricated composites were mechanically characterized for tensile, hardness and shear testing while microstructural characterization was performed by optical and electron microscopy to observe the proper impregnation of Kevlar fibers with epoxy resin and observe the dispersion quality of MWCNTs. Finally the mechanical property results were discussed in relation with microstructural evolution of the composites to acquire a better understanding of the combined reinforcing effect of nanometer size, i.e. MWCNTs and micrometer size, i.e. Kevlar fibers in multiscale composites.

\section{Experimental}

\subsection{Materials}

Plain-woven Kevlar fabric was used as the micrometersize reinforcement (Figure 1a). MWCNTs were procured from Chengdu Organic chemicals, China; the diameter of MWCNTs was $\sim 40 \mathrm{~nm}$ with length of $50-200 \mu \mathrm{m}$ and a purity level $>95 \%$ (Figure 1 b). Aradur ${ }^{\circledR} 5052$ epoxy resin having a viscosity of $40-60 \mathrm{mPas}$ at $25^{\circ} \mathrm{C}$ (ISO 12058-1) with a curing agent Aradur ${ }^{\circledR} 5052$ was used in the present investigation.
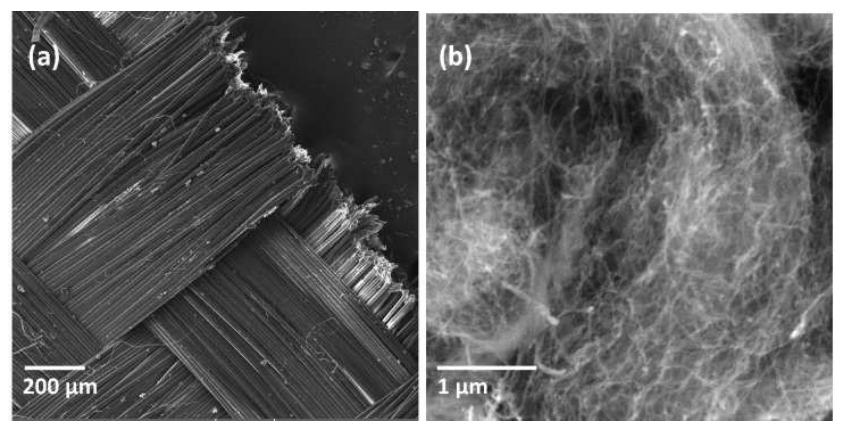

Figure 1. (a) SEM micrograph of Kevlar fabric and (b) SEM micrograph of $M W C N T$ s used for the manufacturing of multiscale Kevlar fiber epoxy matrix composites containing MWCNTs.

\subsection{Manufacturing}

Ultraviolet-ozone treatment was performed to functionalize MWCNTs, which were exposed to ultravioletozone environment for $2 \mathrm{~h}$ at an external oxygen pressure of 1 bar. After functionalization, MWCNTs were added in epoxy resin and ultrasonication was carried out for $30 \mathrm{~min}$ to disperse MWCNTs in epoxy. Curing agent was later added in the epoxy resin containing MWCNTs. A combination of hand layup and vacuum bagging technique was used to fabricate composites. For hand layup, the mold was cleaned with acetone, which was followed by the application of polyvinyl acetate as mold releasing agent. Kevlar fabric was cut in required dimensions and the mixture of epoxy and hardener containing MWCNTs was applied on the fabric using a brush. Impregnation of three layers of the fabric was performed with epoxy, which were subsequently stacked in the mold followed by smoothening with a manual roller. Peel ply, breather and vacuum bag were placed over the fabric layers to seal down the setup using the tacky tape. The vacuum bag was cut, taped down and a small hole was pierced to insert the vacuum hose. The vacuum pump was connected with the sealed mold containing fabric layers and operated for $3 \mathrm{~h}$. Later vacuum pump was removed and the mold was sealed again and left for $24 \mathrm{~h}$ in vacuum. Subsequently, the composite samples were removed carefully 
and cured in vacuum oven at $50^{\circ} \mathrm{C}$ for $12 \mathrm{~h}$ and at $100^{\circ} \mathrm{C}$ for 4h. Three composite samples containing $0.33 \mathrm{wt} \%, 0.66 \mathrm{wt} \%$ and $0.99 \mathrm{wt} \%$ MWCNTs were prepared while one composite sample without MWCNTs was manufactured for comparison. A schematic diagram of manufacturing multiscale composites is shown in Figure 2.
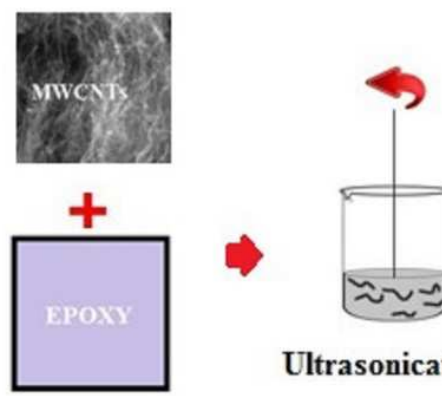

Ultrasonication

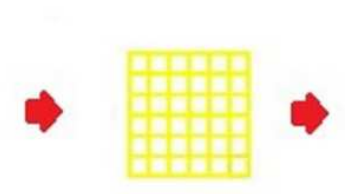

Woven Kevlar

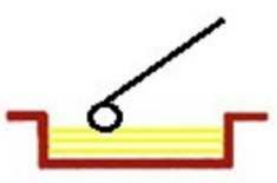

Hand layup

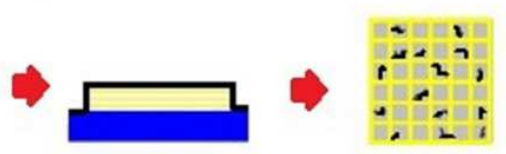

Vacuum bagging
Multiscale composite

Figure 2. Schematic diagram of the fabrication of multiscale Kevlar fiber epoxy matrix composites containing MWCNTs.

\subsection{Characterization}

Optical images of the composites were acquired using a metallurgical microscope (IMM-901 METKON). The samples were mounted, ground and polished for observing the microstructures. Scanning electron microscopy (SEM) was performed on the fracture surfaces of composite samples containing $0.99 \mathrm{wt} \%$ of MWCNTs. SEM images were captured in a field emission gun scanning electron microscope (MIRA3 TESCAN) in a secondary electron imaging mode at an accelerating voltage of $5 \mathrm{kV}$. The samples were placed on stubs and sputter-coated with carbon to make them conductive using a sputter coating machine (Q150 QUORUM).

Tensile tests were performed on a universal tensile testing machine (WDW-30 JINAN). The gauge length of each sample was kept as $60 \mathrm{~mm}$, while width and thickness were $12 \mathrm{~mm}$ and $0.65 \mathrm{~mm}$, respectively. Tabs were applied at both ends of the samples; $100 \mathrm{~mm}$ length of each side of tensile sample was clamped in the grips and the strain rate was kept at $1 \mathrm{~mm} / \mathrm{min}$ during tests. For statistical analysis, the tensile test was performed on five specimens, which were cut from each composite and their average was taken to achieve reliable results.

Hardness testing was performed on Vickers hardness testing machine (HV-1000Z). Specimens from the composite materials were mounted for hardness testing. At least five values of each of the composite specimen were taken. The dwell time was kept at $10 \mathrm{~s}$ and the load was $5 \mathrm{~kg}$. Diagonal length of indent was observed under optical microscope of the hardness testing machine and the hardness values were calculated using the following expression:

$$
\mathrm{HV}=1.8544 \mathrm{P} / \mathrm{d}^{2}
$$

where $\mathrm{P}$ is the load applied and $\mathrm{d}$ is the diagonal length of the indent.

Interlaminar shear test was performed on universal tensile testing machine (WDW-30 JINAN). Specimens with a gauge length, width and thickness of $60 \mathrm{~mm}, 12 \mathrm{~mm}$ and $0.65 \mathrm{~mm}$, respectively were cut for interlaminar shear testing from the composites and clamped from both sides in the tensile testing machine. A strain rate of $1 \mathrm{~mm} / \mathrm{min}$ was applied during shear test.

\section{Results and Discussion}

\subsection{Microstructural Observation}

\subsubsection{Optical Microscopy}

The optical micrograph of multiscale $0.99 \mathrm{wt} \%$ MWCNT Kevlar fiber epoxy matrix composite is shown in Figure 3. It can be seen that Kevlar fibers are properly impregnated with epoxy. No indication of the presence of porosity was noted. Individual fibers in a tow can be seen; the diameter of single Kevlar fiber is $\sim 12 \mu \mathrm{m}$ while individual tow contains $\sim 300$ Kevlar fibers.

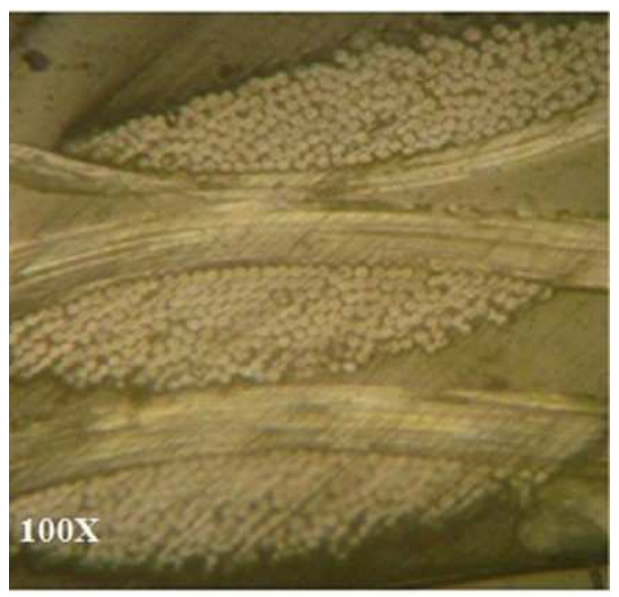

Figure 3. Optical micrograph of multiscale Kevlar fiber epoxy matrix composite containing $0.99 \mathrm{wt} \% \mathrm{MWCNTS}$.

\subsubsection{Scanning Electron Microscopy}

SEM images of multiscale Kevlar fiber epoxy matrix composite containing $0.99 \mathrm{wt} \%$ MWCNTs at two different magnifications are shown in Figure 4. Epoxy resin can be seen in-between the fibers indicating proper impregnation of the fibers. In image at low magnification, MWCNTs could not be identified, however in image at high magnification, MWCNTs can be seen on the fibers and in the matrix. However, images at 
still higher magnifications were acquired to clearly reveal MWCNTs, as shown and discussed further below.
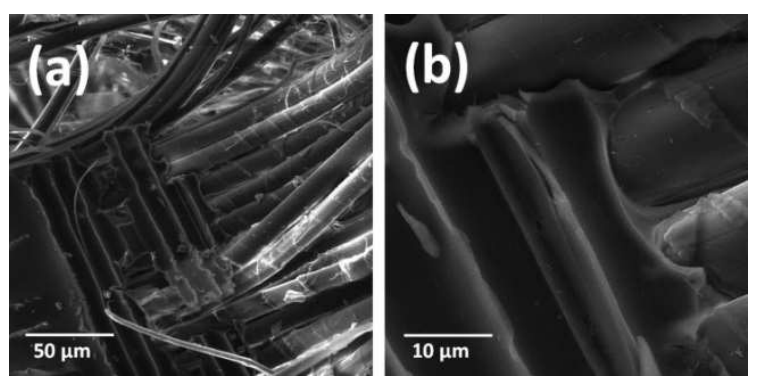

Figure 4. SEM micrographs of multiscale Kevlar fiber epoxy matrix composites containing $0.99 \mathrm{wt} \%$ MWCNTs indicating impregnation of Kevlar fibers in epoxy matrix.

\subsection{Mechanical Characterization}

\subsubsection{Tensile Properties}

Tensile properties of multiscale Kevlar fiber epoxy matrix composites containing MWCNTs are shown in Figure 5. It can be seen that the systematic rise in the loading of MWCNTs from $0.33 \mathrm{wt} \%$ to $0.99 \mathrm{wt} \%$ increased tensile strength of the composites. The reference composite without MWCNTs showed a value of $104 \pm 10$, which increased to $110 \pm 8 \mathrm{MPa}$ after adding $0.33 \mathrm{wt} \%$ MWCNTs demonstrating a rise of $\sim 5.7 \%$ rise. Further increases in MWCNT loadings to $0.66 \mathrm{wt} \%$ and $0.99 \mathrm{wt} \%$ increased the tensile strength values to $132 \pm 6 \mathrm{MPa}$ and $149 \pm 7 \mathrm{MPa}$ showing $\sim 27 \%$ and $\sim 45 \%$ improvements, respectively.

A similar rising trend was observed in elastic modulus of the composites as noted in tensile strength values. AN increase of $\sim 12 \%$ in tensile modulus was observed with the addition of $0.33 \mathrm{wt} \%$ MWCNTs $(4.0 \pm 0.1 \mathrm{GPa})$ in comparison to reference composite $(3.6 \pm 0.1 \mathrm{GPa})$. Further rise in the contents of MWCNTs increased the elastic modulus values to $4.1 \pm 0.1 \mathrm{GPa}$ and $4.3 \pm 0.1 \mathrm{GPa}$ showing improvements of $\sim 13 \%$ and $\sim 17 \%$, respectively.

An increase in the fracture strain is usually observed in epoxy matrix composites containing MWCNTs [6]. The same observation was noticed in the present investigation that the increase in MWCNT contents improved the fracture strain of composites to $6.4 \pm 0.2 \%, \quad 7.0 \pm 0.2 \%$ and $7.7 \pm 0.2 \%$, respectively ( $\sim 14 \%, \sim 24 \%$ and $\sim 36 \%$ improvements) with rising contents of MWCNTs in comparison to reference composite $(5.6 \pm 0.3 \%)$. The flexible nature of MWCNTs is attributed to the increased fracture strain of the composites. However, the presence of Kevlar fibers along with MWCNTs are expected to increase the fracture strain in the present study as both the micrometer and nanometer size reinforcements elongate considerably before fracture.

In a different research investigation, iron-coated MWCNTs were grown on Kevlar fabric and embedded in polyester resin to manufacture composites by vacuum assisted resin transfer molding; the composites showed an increase in tensile strength up to $\sim 122 \%$ and tensile modulus up to $\sim 90 \%$ [21]. Another work on Kevlar fiber epoxy matrix composites containing silane-modified $\mathrm{Fe}_{2} \mathrm{O}_{3}$ nanoparticles showed an increase of $\sim 29 \%$ in tensile strength by the addition of only $1.5 \mathrm{wt} \% \mathrm{Fe}_{2} \mathrm{O}_{3}$ nanoparticles in comparison to the reference composite without nanoparticles. Further increase in $\mathrm{Fe}_{2} \mathrm{O}_{3}$ resulted in decrease in tensile strength due to their agglomeration [22]. The present research showed increase in tensile properties with the addition of MWCNTs. The strengthening effect originated due to the presence of MWCNTs in epoxy matrix, which increased the tensile properties of matrix, and which in turn enhanced the tensile performance of multiscale composites.
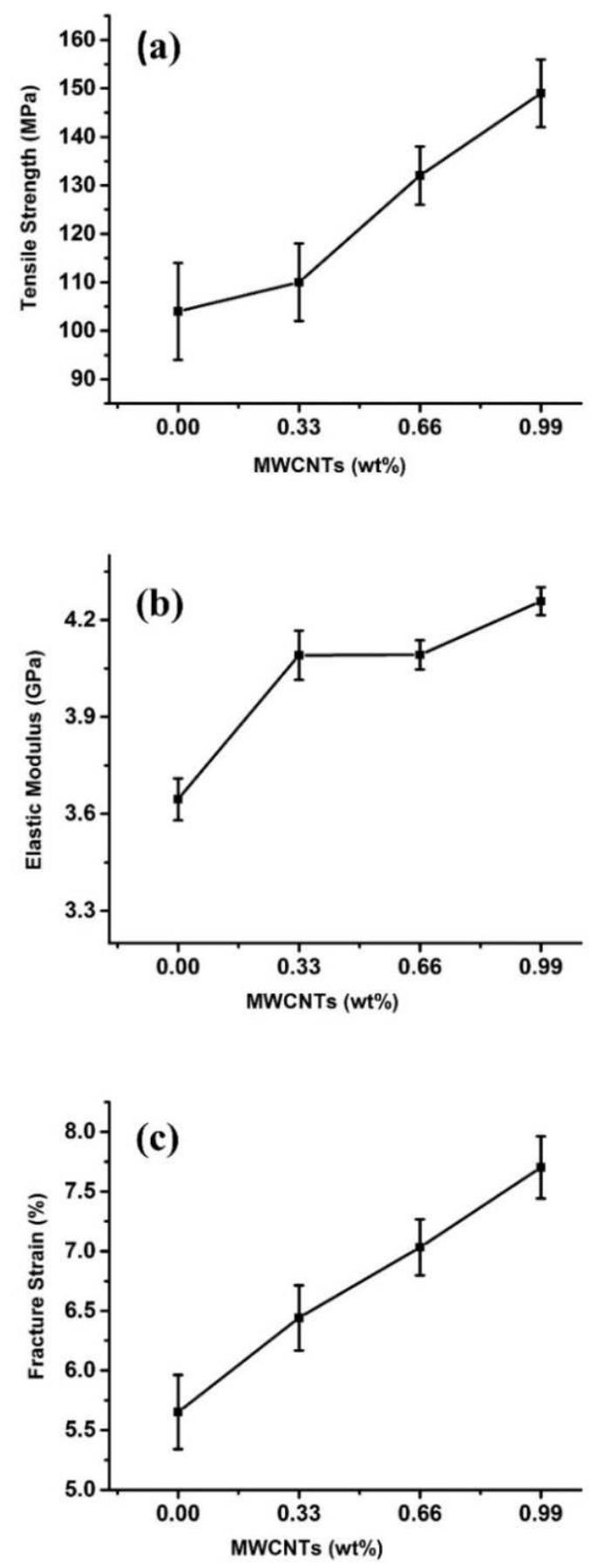

Figure 5. Tensile properties of multiscale Kevlar fiber epoxy matrix composites containing $0.33 w t \%, 0.66 w t \%$ and $0.99 w t \%$ MWCNTs: (a) tensile strength (b) elastic modulus, and (c) fracture strain. 


\subsubsection{Hardness}

The systematic rise in the contents of MWCNTs in Kevlar fiber epoxy matrix composites increased their hardness (Figure 6). The hardness value of reference composite without MWCNTs was found to be $14.2 \pm 0.7 \mathrm{Hv}$, which increased to $19.9 \pm 0.5 \mathrm{HV}(\sim 39 \%$ rise $)$ by the addition of $0.33 \%$ MWCNTs. On further increasing the concentration of MWCNTs to $0.66 \mathrm{wt} \%$ and $0.99 \mathrm{wt} \%$, the hardness values increased to $21.4 \pm 0.6 \mathrm{Hv}$ and $22.8 \pm 0.4 \mathrm{Hv}$ ( $\sim 50 \%$ and $\sim 60 \%$ rise), respectively. It can be inferred that the hardness of the epoxy matrix increased due to the presence of MWCNTs, as was observed in tensile properties, which increased the hardness of the multiscale composites. Although the hardness value of MWCNTs is not known experimentally but it has been observed that the incorporation of MWCNTs in epoxy matrix increases the hardness of the composites [8]. In contrast to MWCNTs, the hardness value of individual Kevlar fiber is available, which was found experimentally by nanoindentation to be $1.3 \pm 0.7 \mathrm{GPa}[23]$.

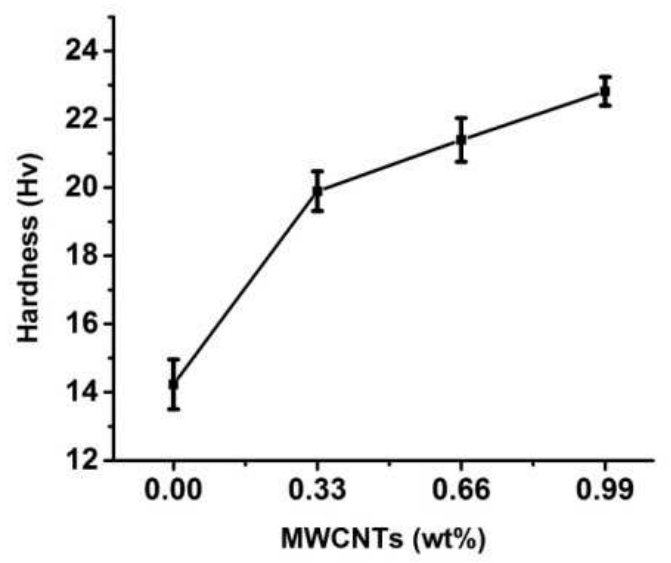

Figure 6. Hardness values of Kevlar fiber epoxy matrix composites with and without adding MWCNTs.

Literature reveals that the hardness of polymeric matrix composites increases by the addition of CNTs [24]. In a study, the hardness value of neat epoxy was reported to be $11.5 \pm 0.4 \mathrm{Hv}$, which increased to $14.1 \pm 0.3 \mathrm{Hv}$ ( $\sim 22 \%$ rise) by adding $0.1 \mathrm{wt} \%$ CNTs [8]. In a different study on carbon fiber epoxy matrix composites, the hardness value of $21 \pm 1 \mathrm{Hv}$ of composites increased to $24 \pm 2 \mathrm{Hv}$ after adding $0.5 \mathrm{wt} \%$ MWCNTs showing a rise of $\sim 14 \%$. Further rises in the concentration of MWCNTs to $1.0 \mathrm{wt} \%$ and $1.5 \mathrm{wt} \%$ uninterruptedly increased the hardness values to $28 \pm 2 \mathrm{Hv}$ and $31 \pm 2 \mathrm{Hv} \quad(\sim 33 \%$ and $\sim 47 \%$ rises $)$, respectively. However, hardness value of composite containing $2.0 \mathrm{wt} \%$ MWCNTs decreased to $26 \pm 3 \mathrm{Hv}$, which was attributed to the formation of MWCNT-agglomerates [4]. The increasing trend of hardness in composites containing CNTs is observed until their uniform dispersion. However, in case of poor dispersion, a reverse trend is observed by increasing the fraction of CNTs. Generally by increasing the concentration of CNTs, their uniform dispersion becomes difficult and probability of agglomeration increases [25].
The extent of loading is therefore defined by dispersion methods and dispersion quality of CNTs.

\subsubsection{Interlaminar Shear Strength}

Figure 7 shows the effect of MWCNTs on the interlaminar shear strength of the Kevlar fiber epoxy matrix composite. It has been observed that the incorporation of MWCNTs in the composite has improved the interlaminar shear strength. The reference sample without any MWCNTs has a shear strength value of $23 \mathrm{MPa}$, which increased to $35 \mathrm{MPs}$ by the addition of $0.99 \mathrm{wt} \%$ MWCNTs. A systematic increase in the values of ILSS is observed when the weight percentage of MWCNTs is increased from $0.33 \mathrm{wt} \%$ to $0.99 \mathrm{wt} \%$. This enhancement in the ILSS is dominated by the anchoring and bridging effect of MWCNTs in between the layers of multiscale Kevlar fiber epoxy composite.

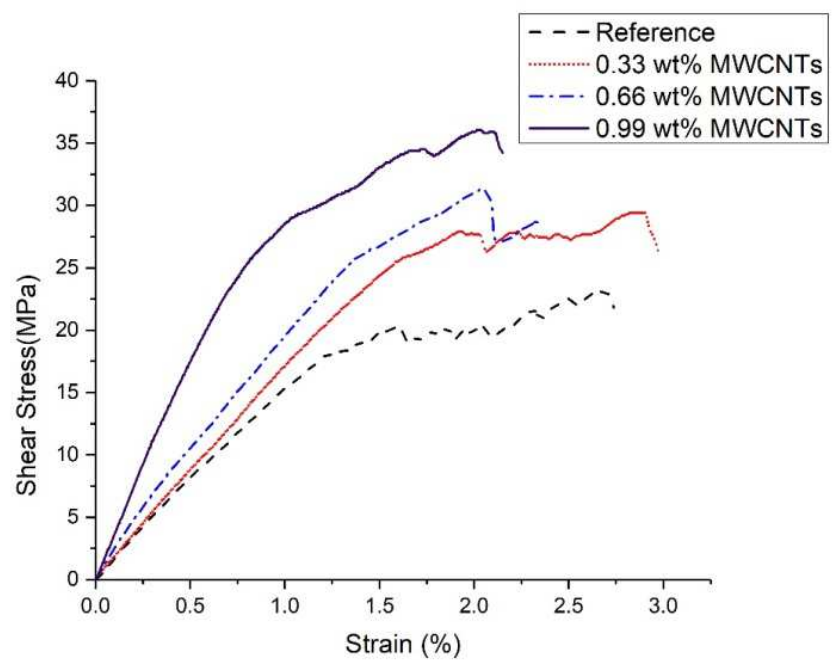

Figure 7. Interlaminar shear stress values of Kevlar fiber epoxy matrix composites with and without adding MWCNTs.
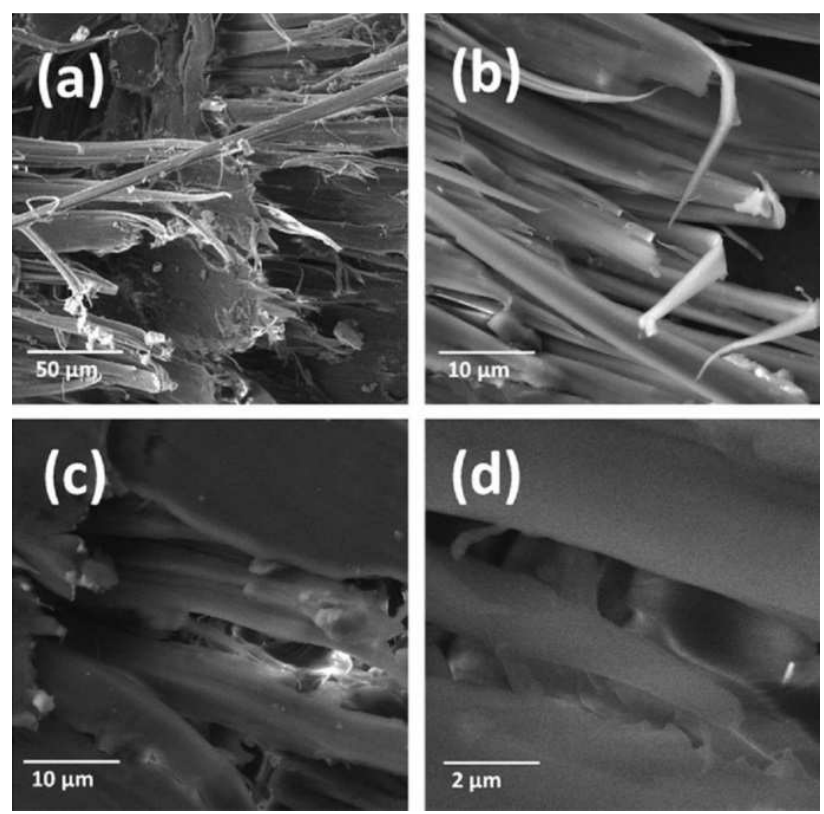

Figure 8. (a-d) SEM images of fracture surfaces of multiscale Kevlar fiber epoxy matrix composites containing $0.99 w t \%$ MWCNTs at different magnifications. 


\subsubsection{Fractgraphy}

Figure 8 shows SEM images of the fracture surface of multiscale Kevlar fiber epoxy matrix composite containing $0.99 \mathrm{wt} \%$ MWCNTs after tensile failure. Individual Kevlar fibers are pulled out indicating fracture strain before failure, which is the typical characteristic of tough Kevlar fibers, as opposed to glass and carbon fibers, where fracture is of brittle nature [8]; in contrast, Kevlar fibers fracture before absorbing energy [26]. Moreover, Kevlar fibers do not fracture normal to the direction of applied load. Instead, longitudinal splits are developed within the fibers before final fracture.
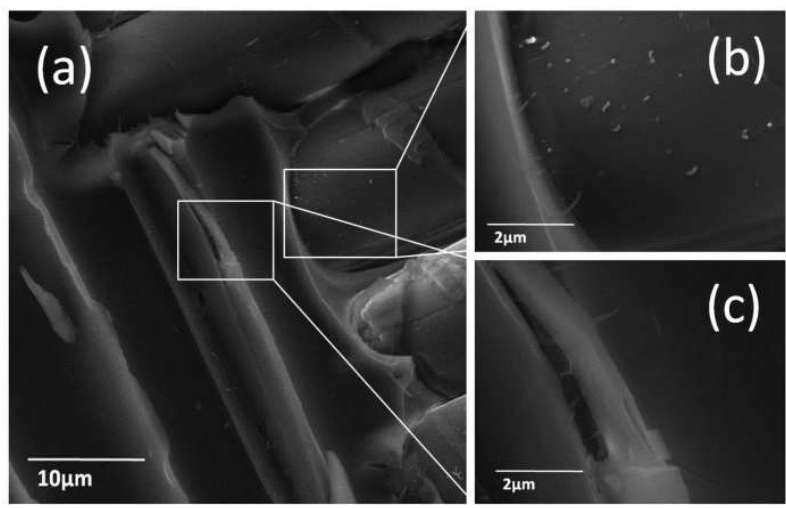

Figure 9. SEM images of fracture surfaces of multiscale Kevlar fiber epoxy matrix composites containing 0.99wt\% MWCNTs at (a) low and high magnifications showing the (b) adherence of MWCNTs to individual Kevlar fiber and (c) pull out phenomenon from epoxy matrix.

\subsubsection{Strengthening and Toughening Effect Due to MWCNTS}

Figure 9 shows SEM images of the fracture surface of multiscale Kevlar fiber epoxy matrix composite containing $0.99 \mathrm{wt} \%$ MWCNTs. MWCNTs are observed within the matrix and also on the individual Kevlar fibers. The presence of MWCNTs in epoxy matrix is obvious, as these were dispersed in epoxy before incorporating Kevlar fibers in MWCNT-loaded epoxy. However, the presence of MWCNTs on individual Kevlar fibers suggests that during fracture, MWCNTs were pulled out of the epoxy matrix but remained intact with the fibers. Such behavior is expected to increase the interlaminar shear properties of the composites if the adherence of MWCNTs with Kevlar fibers is reasonably strong. The phenomenon of pullout is one of the toughening mechanisms of composites and the emergence of this phenomenon in the fracture of epoxy indicates the emergence of toughening behavior in epoxy and the resultant multiscale composites. Finally, no indication of the agglomerates of MWCNTs was noted at the loading of $0.99 \mathrm{wt} \%$, which ensures their good dispersion. It also indicates that the functionalization process of MWCNTs by ozonetreatment was adequate. A study on carbon fiber epoxy matrix composites containing CNTs previously showed homogeneous dispersion up to $1.5 \mathrm{wt} \%$ CNT loading with simultaneous increase in mechanical properties while further increase in the contents of CNTs resulted in their agglomerates, which decreased the mechanical performance of composites [4]. In the present study, loading of CNTs was $0.99 \mathrm{wt} \%$ and a uniform dispersion was also achieved.

\section{Conclusions}

The incorporation of MWCNTs up to $0.99 \mathrm{wt} \%$ in Kevlar fiber epoxy matrix composites increased the mechanical performance of novel multiscale composites. In comparison to reference composite without nanoreinforcement, the multiscale composites containing $0.99 \mathrm{wt} \%$ MWCNTs showed the rises in tensile strength, hardness and interlaminar shear strength up to $45 \%, 60 \%$ and $13 \%$, respectively. Uniform dispersion of MWCNTs in the matrix is the possible reason of improvement in tensile and hardness of Kevlar fiber epoxy matrix composites while the adherence of MWCNTs with Kevlar fibers providing anchoring effect between Kevlar fibers and epoxy matrix increased the interlaminar shear strength. The presence of MWCNTs in epoxy matrix is one of the possible schemes to increase the mechanical properties of traditional Kevlar fibers epoxy matrix composites wherein the increased strengthening effect is derived from novel nanometer-scale reinforcement.

\section{Declarations}

\section{Conflict of Interest}

The authors declare that they have no competing interests.

\section{Availability of Data and Material}

All data included in this manuscript is in original form and has been recorded by the instruments listed in the research article.

\section{Ethics Approval}

All research ethics are followed and strictly adhered to while working on this manuscript.

\section{Consent to Participate}

All authors have participated equally in producing this research work and there is no conflict in participation.

\section{Consent for Publication}

All authors have provided their consent for publication.

\section{References}

[1] Awan, F. S. \& Subhani, T.: Preparation and Characterization of Carbon Nanotube Deposited Carbon Fiber Reinforced Epoxy Matrix Multiscale Composites. Advanced Nano Research. 1, 14-22 (2018).

[2] Ma, P.-C., Siddiqui, N. A., Marom, G. \& Kim, J.-K.: Dispersion and functionalization of carbon nanotubes for polymer-based nanocomposites: a review. Composites Part A: Applied Science and Manufacturing. 41, 1345-1367 (2010).

[3] Najafi, E., Kim, J.-Y., Han, S.-H. \& Shin, K.: UV-ozone treatment of multi-walled carbon nanotubes for enhanced organic solvent dispersion. Colloids and Surfaces A: Physicochemical and Engineering Aspects. 284, 373-378 (2006). 
[4] Subhani, T., Shaukat, B., Ali, N. \& Khurram, A. A.: Toward improved mechanical performance of multiscale carbon fiber and carbon nanotube epoxy composites. Polymer Composites. 38, 1519-1528 (2017).

[5] McAllister, Q. P., Gillespie, J. W. \& VanLandingham, M. R.: The sub-micron scale energy dissipative deformation mechanisms of Kevlar fibrils. Journal of Materials Science. 48, 6245-6261 (2013).

[6] Lin, T., Wu, S., Lai, J. \& Shyu, S.: The effect of chemical treatment on reinforcement/matrix interaction in Kevlarfiber/bismaleimide composites. Composites Science and Technology. 60, 1873-1878 (2000).

[7] Yue, C. Y. \& Padmanabhan, K.: Interfacial studies on surface modified Kevlar fibre/epoxy matrix composites. Composites Part B: Engineering. 30, 205-217 (1999).

[8] T. Subhani, M. Latif, I. Ahmad, S. A. Rakha, N. Ali, and A. A. Khurram,: Mechanical performance of epoxy matrix hybrid nanocomposites containing carbon nanotubes and nanodiamonds. Materials \& Design, 87, 436-444, (2015).

[9] Guo, P., Chen, X., Gao, X., Song, H. \& Shen, H.: Fabrication and mechanical properties of well-dispersed multiwalled carbon nanotubes/epoxy composites. Composites science and Technology. 67, 3331-3337 (2007).

[10] Liu, Y., Xiao, H.-M., Feng, Q.-P. \& Fu, S.-Y.: Synergistic effect of carbon nanotubes and n-butyl glycidyl ether on matrix modification for improvement of tensile performance of glass fiber/epoxy composites. Composites Part A: Applied Science and Manufacturing. 62, 39-44 (2014).

[11] Davis, D. C., Wilkerson, J. W., Zhu, J. \& Hadjiev, V. G.: A strategy for improving mechanical properties of a fiber reinforced epoxy composite using functionalized carbon nanotubes. Composites Science and Technology. 71, 10891097 (2011).

[12] Sharma, S. \& Lakkad, S.: Effect of CNTs growth on carbon fibers on the tensile strength of CNTs grown carbon fiberreinforced polymer matrix composites. Composites Part A: Applied Science and Manufacturing. 42, 8-15 (2011).

[13] F. S. Awan, M. A. Fakhar, L. A. Khan, U. Zaheer, A. F. Khan, and T. Subhani.: Interfacial mechanical properties of carbon nanotube-deposited carbon fiber epoxy matrix hierarchical composites. Composite Interfaces. 25, 681-699 (2018).

[14] M. Khan, A. A. Khurram, T. Li, T. Zhao, T. Subhani, I. Gul, Z. Ali and V. Patel.: Synegistic effect of organic and inorganic nano fillers on the dielectric and mechanical properties of epoxy composites, Journal of Materials Science \& Technology. 34, 2424-2430 (2018).

[15] R. Giovanardi, M. Montorsi, G. Ori, J. Cho, T. Subhani, A. R.
Boccaccini and C. Siligardi.: Microstructural characterisation and electrical properties of multiwalled carbon nanotubes/glass-ceramic nanocomposites. Journal of Materials Chemistry. 20, 308-313 (2010).

[16] M. Rahman, S. Zainuddin, M. Hosur, C. Robertson, A. Kumar, J. Trovillion and S. Jeelani.: Effect of NH2-MWCNTs on crosslink density of epoxy matrix and ILSS properties of e-glass/epoxy composites. Composite Structures. 95, 213-221 (2013).

[17] Q. Zhang, J. Wu, L. Gao, T. Liu, W. Zhong, G. Sui and X. Yang.: Influence of a liquid-like MWCNT reinforcement on interfacial and mechanical properties of carbon fiber filament winding composites. Polymer. 90, 193-203 (2016).

[18] Taraghi, I., Fereidoon, A. \& Taheri-Behrooz, F.: Low-velocity impact response of woven Kevlar/epoxy laminated composites reinforced with multi-walled carbon nanotubes at ambient and low temperatures. Materials \& Design. 53, 152-158 (2014).

[19] Reis, P., Ferreira, J., Santos, P., Richardson, M. \& Santos, J.: Impact response of Kevlar composites with filled epoxy matrix. Composite Structures. 94, 3520-3528 (2012).

[20] Reis, P., Ferreira, J., Zhang, Z., Benameur, T. \& Richardson, M.: Impact response of Kevlar composites with nanoclay enhanced epoxy matrix. Composites Part B: Engineering. 46, 7-14 (2013).

[21] Hazarika, A., Deka, B. K., Kim, D., Park, Y.-B. \& Park, H. W.: Microwave-induced hierarchical iron-carbon nanotubes nanostructures anchored on polypyrrole/graphene oxidegrafted woven Kevlar ${ }^{\circledR}$ fiber. Composites Science and Technology. 129, 137-145 (2016).

[22] Jaisingh, S. J., Thyagarajan, K., Selvam, V. \& Kumar, M. S. C.: Mechanical properties of glass fibre reinforced Unsaturated Polyester toughened epoxy/siliconized iron (III) oxide nanocomposites. Life Science Journal. 10 (2013).

[23] J. Bencomo-Cisneros, A. Tejeda-Ochoa, J. García-Estrada, C. Herrera-Ramírez, A. Hurtado-Macías, R. Martínez-Sánchez and J. Herrera-Ramírez.: Characterization of Kevlar-29 fibers by tensile tests and nanoindentation. Journal of Alloys and Compounds. 536, S456-S459 (2012).

[24] M. Biercuk, M. C. Llaguno, M. Radosavljevic, J. Hyun, A. T. Johnson and J. E. Fischer.: Carbon nanotube composites for thermal management. Applied physics letters. 80, 2767-2769 (2002).

[25] Y.-J. Zhai, Z.-C. Wang, W. Huang, J.-J. Huang, Y.-Y. Wang and Y.-Q. Zhao.: Improved mechanical properties of epoxy reinforced by low content nanodiamond powder. Materials Science and Engineering: A. 528, 7295-7300 (2011).

[26] Greenhalgh, E.: Failure analysis and fractography of polymer composites. (Elsevier, 2009). 